Darmawan, et al/Jurnal Ekonomi Syariah Teori dan Terapan Vol. 6 No. 11 November 2019: 2291-2302;

ZAKAT PRODUKTIF DALAM KEBERHASILAN USAHA MUSTAHIQ DITINJAU DARI INDIKATOR PENINGKATAN MODAL, PENINGKATAN PENDAPATAN, PENINGKATAN JUMLAH KONSUMEN, PENINGKATAN PRODUKSI DAN PENINGKATAN AMAL JARIYAH MUSTAHIQ (STUDI KASUS LAZ INISIATIF ZAKAT INDONESIA CABANG JAWA TIMUR)

\title{
ZAKAT PRODUKTIF DALAM KEBERHASILAN USAHA MUSTAHIQ DITINJAU DARI INDIKATOR PENINGKATAN MODAL, PENINGKATAN PENDAPATAN, PENINGKATAN JUMLAH KONSUMEN, PENINGKATAN PRODUKSI DAN PENINGKATAN AMAL JARIYAH MUSTAHIQ (STUDI KASUS LAZ INISIATIF ZAKAT INDONESIA CABANG JAWA TIMUR)'
}

\author{
Rachmat Darmawan \\ Departemen Ekonomi Syariah - Fakultas Ekonomi dan Bisnis - Universitas Airlangga \\ Email: rachmat.darmawan-2014@feb.unair.ac.id

\section{Sunan Fanani} \\ Departemen Ekonomi Syariah - Fakultas Ekonomi dan Bisnis - Universitas Airlangga \\ Email: sunan.fanani@feb.unair.ac.id
}

\begin{abstract}
:
This study aims to analyze the role of productive zakat managed by LAZ IZI, which has a role in increasing the success of mustahiq businesses in the city of Surabaya. There are five standards that can be used to measure the increase in business success of mustahia, namely the standard of increasing capital, increasing income, increasing production, increasing the number of consumers and charity jariyah mustahiq. This study uses a qualitative approach with a case study method. The technique of collecting data uses direct interviews, documentation and observation. The analysis technique used is narrativedescriptive analysis. Then to find out the validity of the data, the researcher used the triangulation technique by cross checking the findings of primary data and secondary data. The results of this study were that the three informants experienced an increase in capital, an increase in income, an increase in production, an increase in the number of consumers and an increase in charity after receiving assistance. The informants felt the business they had run had success. The success of the informant's business can be seen from the increase in all indicators mentioned. Supervision and mentoring carried out by LAZ IZI Surabaya was felt very useful in motivating and encouraging continuous effort. In addition, they are able to set aside a portion of the assets to be given to those who are entitled.
\end{abstract}

Keywords: Productive Zakat, Mustahiq, Utilization, Business Success

\section{PENDAHULUAN}

Pertumbuhan

ekonomi

merupakan faktor perkembangan dari suatu kegiatan dalam perekonomian yang menyebabkan barang dan jasa yang diproduksi dalam suatu masyarakat akan bertambah, sehingga akan meningkatkan kemakmuran dan kesejahteraan pada masyarakat tersebut (Soekirno, 1994). Lalu menurut (Lincolin, 1997) pertumbuhan ekonomi yang diartikan sebagai kenaikan GDP terhadap GNP tanpa memandang apakah kenaikan tersebut lebih besar atau lebih kecil dari tingkat pertumbuhan penduduk, dan apakah akan merubah struktur ekonomi atau tidaknya.

Tingkat pertumbuhan ekonomi seringkali dijadikan sebagai tolak ukur suatu Negara agar bisa dikatakan sebagai Negara yang berkembang atau

\footnotetext{
${ }^{1}$ Jurnal ini merupakan bagian dari skripsi yang ditulis oleh Rachmat Darmawan, NIM: 041411431032, yang diuji pada 17 Juli 2019.
} 
Darmawan, et al/Jurnal Ekonomi Syariah Teori dan Terapan Vol. 6 No. 11 November 2019: 2291-2302; ZAKAT PRODUKTIF DALAM KEBERHASILAN USAHA MUSTAHIQ DITINJAU DARI INDIKATOR PENINGKATAN MODAL, PENINGKATAN PENDAPATAN, PENINGKATAN JUMLAH KONSUMEN, PENINGKATAN PRODUKSI DAN PENINGKATAN AMAL JARIYAH MUSTAHIQ (STUDI KASUS LAZ INISIATIF ZAKAT INDONESIA CABANG JAWA TIMUR)

bahkan sebagai Negara maju dapat dilihat pada tingkat kesejahteraan masyarakatnya. Tingkat pendapatan masyarakat juga menjadi permasalahan umum terhadap masalah sosial yang menyebabkan pengaruh besar terhadap tingkat konsumsi masyarakat tersebut, sehingga dibutuhkan solusi dalam menghadapi permaslahan di era globalisasi ini. Indonesia berada pada posisi yang sangat riskan terhadap segala fenomena yang bisa mempengaruhi berbagai sektor yang ada di Negara ini, terutama pada perekonomian di masyarakat.

\section{Tabel 1.}

Laju Pertumbuhan Ekonomi Indonesia PDB berdasarkan Lapangan Usaha

\begin{tabular}{|c|c|c|}
\hline \multirow{2}{*}{ Triwulan } & \multicolumn{2}{|c|}{$\begin{array}{c}\text { Laju Pertumbuhan } \\
\text { Ekonomi Indonesia PDB } \\
\text { berdasarkan Lapangan } \\
\text { Usaha (y on y) }\end{array}$} \\
\cline { 2 - 3 } & $\mathbf{2 0 1 7}$ & $\mathbf{2 0 1 8}$ \\
\hline I & $5.01 \%$ & $5.06 \%$ \\
\hline II & $5.01 \%$ & $5.27 \%$ \\
\hline III & $5.06 \%$ & $5.17 \%$ \\
\hline IV & $5.19 \%$ & - \\
\hline
\end{tabular}

Sumber : BPS, data diolah peneliti

Berdasarkan pada tabel 1 bisa disimpulkan bahwa pertumbuhan ekonomi mengalami peningkatan. Hal ini dibuktikan dengan pada tahun 2017 Triwulan I berada pada tingkat 5.01\%; sedangkan Triwulan II masih tetap di tingkat 5.01\%; dan pada Triwulan III dan IV mencapai tingkat $5.06 \%$ dan $5.19 \%$. Pada tahun 2018 mengalami peningkatan, dapat dilihat Triwulan I mencapai 5.06\% ; pada Triwula II mencapai $5.27 \%$; dan pada Triwulan III turun sebesar 5.17\%.

\section{Tabel 2.}

Presentase Penduduk Miskin di Kota Surabaya (\%)

\begin{tabular}{|l|c|c|c|}
\hline \multirow{2}{*}{$\begin{array}{l}\text { Nama } \\
\text { Wilayah }\end{array}$} & \multicolumn{3}{|c|}{$\begin{array}{l}\text { Presentase Penduduk Miskin di } \\
\text { Kota Surabaya (\%) }\end{array}$} \\
\cline { 2 - 4 } & $\mathbf{2 0 1 6}$ & $\mathbf{2 0 1 7}$ & $\mathbf{2 0 1 8}$ \\
\hline Surabaya & 5.82 & 5.63 & 5.39 \\
\hline
\end{tabular}

Sumber : BPS, diolah oleh peneliti

Berdasarkan tabel 2 presentase penduduk miskin di kota Surabaya mengalami penurunan dari tahun 2016 sebesar 5.82\%, tahun 2017 mengalami penurunan menjadi 5.63\% dan tahun 2018 juga mengalami penurunan $5.39 \%$.

Kemiskinan merupakan kondisi dimana kehidupan seseorang yang serba kekurangan. Menurut Sumodiningrat (1999:18-23), kemiskinan merupakansalah satu bahaya besar dan dapat mempengaruhi akidah umat. Salah satu penyebab orang keluar dari agama adalah kemiskinan dan kefakiran. Kemiskinan muncul karena adanya kelompok anggota masyarakat yang secara struktural tidak mempunyai peluang dan kemampuan yang memadai untuk mencapai tingkat kehidupan yang layak. Akibatnya mereka harus mengakui keunggulan kelompok masyarkat lainya dalam persaingan mencari nafkah dan pemilikan aset produksi. Persaingan yang tidak seimbang ini membuat mereka yang tidak unggul kian lama semakin tertinggal. Dalam prosesnya gejala ini menimbulkan persoalan ketimpangan distribusi 
Darmawan, et al/Jurnal Ekonomi Syariah Teori dan Terapan Vol. 6 No. 11 November 2019: 2291-2302; ZAKAT PRODUKTIF DALAM KEBERHASILAN USAHA MUSTAHIQ DITINJAU DARI INDIKATOR PENINGKATAN MODAL, PENINGKATAN PENDAPATAN, PENINGKATAN JUMLAH KONSUMEN, PENINGKATAN PRODUKSI DAN PENINGKATAN AMAL JARIYAH MUSTAHIQ (STUDI KASUS LAZ INISIATIF ZAKAT INDONESIA CABANG JAWA TIMUR)

pendapatan dan selanjutnya kesenjangan kesejahteraan.

Seperti yang sudah dijelakan sebelumnya diatas, salah satu cara menanggulangi kemiskinan adalah dengan menggunakan dana zakat. Zakat adalah sebagian harta milik seseorang yang Allah SWT mewajibkan pemiliknya untuk dikeluarkan dan diberikan kepada yang berhak menerima sesuai dengan syariat Islam. Dengan dikeluarkan dan diberikanya dana zakat tersebut diharapkan mampu mengatasi masalah pemerataan pendapatan dan kemiskinan.

Zakat konsumtif adalah harta zakat secara langsung diperuntukkan bagi mereka yang tidak mampu dan sangat membutuhkan, terutama fakir miskin. Zakat konsumtif digunakan langsung untuk memenuhi kebutuhan pokok hidup mustahik, seperti kebutuhan makanan, pakaian, dan tempat tinggal. Sedangkan zakat produktif adalah pemberian zakat yang dapat membuat para penerimanya menghasilkan sesuatu yang bermanfaat dan dapat dinikmati secara terus menerus, dengan harta zakat yang telah diterimanya. Dengan demikian zakat produktif merupakan zakat dimana harta atau dana zakat yang diberikan kepada para mustahiq tidak dihabiskan, akan tetapi dikembangkan dan digunakan untuk membantu usaha mereka, sehingga dengan usaha tersebut mereka dapat memenuhi kebutuhan hidup secara terus menerus.

Rahardjo (1999:45) menambahkan bahwa zakat produktif adalah dana zakat yang diberikan kepada seseorang atau sekelompok masyarakat kemudian digunakan sebagai modal kerja. Sedangkan menurut Rofiar (2004:259) pendistribusian zakat ada 2 macam yaitu: yang pertama, pendistribusian/ pembagian dalam bentuk konsumtif untuk memenuhi kebutuhan jangka pendek. Lalu yang kedua, pendistribusian dalam bentuk dana untuk kegiatan produktif".

$$
\text { Hafidoh (2015:6) menjelaskan }
$$
bahwa dana zakat untuk kegiaan produktif akan lebih optimal apabila dikelola oleh lembaga amil zakat, karena sebagai organisasi yang tepercaya untuk pengalokasian, pendayagunaan dan pendistribusian dana zakat. Lembaga amil zakat tidak memberikan zakat begitu saja, melainkan juga mendampingi dengan cara memberikan pengarahan agar dana zakat tersebut benar-benar dijadikan modal kerja atau usaha sehingga penerima zakat tersebut memperoleh penghasilan yang layak. Sebaliknya, apabila dana zakat diberikan langsung oleh muzzaki ke mustahik tanpa pendampingan maka penerima zakat akan menggunakan dana zakat yang diterima tanpa pengarahan. 
Darmawan, et al/Jurnal Ekonomi Syariah Teori dan Terapan Vol. 6 No. 11 November 2019: 2291-2302; ZAKAT PRODUKTIF DALAM KEBERHASILAN USAHA MUSTAHIQ DITINJAU DARI INDIKATOR PENINGKATAN MODAL, PENINGKATAN PENDAPATAN, PENINGKATAN JUMLAH KONSUMEN, PENINGKATAN PRODUKSI DAN PENINGKATAN AMAL JARIYAH MUSTAHIQ (STUDI KASUS LAZ INISIATIF ZAKAT INDONESIA CABANG JAWA TIMUR)

\section{LANDASAN TEORI}

Ambara (2009:19) menjelaskan bahwa zakat secara etimologi merupakan bentuk isim masdar dari akar kata yang bermakna an-nama' (barakah), atthaharah (bersih), as-salah (kebaikan), safwatu asy-ya'i (jernihnya sesuatu), dan al-madu (pujian). Hafidhuddin (2002:18) menjelaskan zakat menurut terminologi adalah nama bagi sejumlah harta tertentu yang telah mencapai syarat tertentu yang diwajibkan oleh Allah SWT untuk dikeluarkan dan diberikan kepada yang berhak menerimanya dengan persyaratan tertentu pula. Seseorang yang mengeluarkan zakat, berarti dia telah membersihkan diri, jiwa dan hartanya. Dia telah membersihkan jiwanya dari penyakit kikir dan membersihkan hak orang lain yang ada di dalam hartanya. Orang yang berhak menerimanya pun akan bersih jiwanya dari penyakit dengki, iri hati terhadap orang lain yang mempunyai kelebihan harta.

Zakat adalah ibadah yang memiliki dua hubungan, yaitu vertikal dan horizontal. Zakat merupakan bentuk ketaatan hamba kepada Allah SWT (hablun minallah) dan kewajiban tolong menolong sesama manusia (hablun minannnas). Hidayat (2008) menjelaskan bahwa tujuan zakat secara umum menyangkut tentang ekonomi, sosial, dan kenegaraan maupun secara khusus yang ditinjau dari tujuan-tujuan nash yaitu diantaranya:

1. Ekonomi.

Dilihat dari sisi ekonomi zakat bertujuan mengangkat derajat fakir miskin dan mampu membantu memecahkan masalah para gharim, ibnusabil dan mustahiq lainya. Zakat yang diberikan kepada mustahiq dapat digunakan untuk memenuhi kebutuhan hidup pokok mustahiq maupun digunakan untuk kegiatan produktif sehingga kelak akan meningkatkan derajat dan kesejahteraan mustahiq.

2. Sosial.

Dilhat dari sisi sosial secara umum zakat memiliki tujuan menjembatani jurang antara orang kaya dan orang miskin didalam masyarakat dan membentangkan tali persaudaraan sesama umat islam dan manusia pada umumnya agar tidak ada kesenjangan diantara keduanya. Di sisi lain zakat bagi muzzaki bertujuan menghilangkan sifat kikir orang kaya dan mengembangkan rasa tanggung jawab sosial bagi pemilik harta. Sedangkan bagi mustahiq zakat bertujuan menghilangkan sifat dengki dan iri hati orang miskin.

3. Negara.

Bagi negara zakat bertujuan sebagai sumbangan wajib muslim dan untuk perbendaharaan negara sekaligus mencegah penumpukan kekayaan di tangan sebaagian kecil manusia. 
Darmawan, et al/Jurnal Ekonomi Syariah Teori dan Terapan Vol. 6 No. 11 November 2019: 2291-2302; ZAKAT PRODUKTIF DALAM KEBERHASILAN USAHA MUSTAHIQ DITINJAU DARI INDIKATOR PENINGKATAN MODAL, PENINGKATAN PENDAPATAN, PENINGKATAN JUMLAH KONSUMEN, PENINGKATAN PRODUKSI DAN PENINGKATAN AMAL JARIYAH MUSTAHIQ (STUDI KASUS LAZ INISIATIF ZAKAT INDONESIA CABANG JAWA TIMUR)

Dengan diketahuinya tujuan zakat, maka dapat diketahui bahwa zakat berguna dari kedua sisi baik mustahiq maupun muzzaki.

Pada awalnya prinsip dasar dari dana zakat adalah untuk kegiatan konsumtif. Dalam hal ini memiliki arti bahwa dana zakat pada awalnya digunakan untuk memenuhi kebutuhan pokok hidup mustahiq, seperti makan, tempat tinggal, dan pakaian. Dana zakat digunakan untuk menanggulangi kebutuhan mustahiq yang sifatnya bukan hanya mendesak tetapi juga mendadak. Zakat pada awalnya digunakan untuk kegiatan konsumtif memunculkan pemikiran dan inovasi dalam menyalurkan dana zakat, salah satunya adalah zakat produktif. Dana zakat produktif yang dikelola oleh badan maupun lembaga amil zakat dengan maksud agar dana zakat tersebut tidak habis seketika tetapi dapat dimanfaatkan dalam jangka waktu yang lebih lama. Dana zakat produktif ini kemudian dikembangkan sehingga dana zakat produktif dapat bergulir dari mustahiq ke mustahiq yang lain dan diharapkan mustahiq tersebut kelak akan menjadi muzzaki. Dengan demikian zakat produktif merupakan zakat dimana harta atau dana zakat yang diberikan kepada para mustahiq tidak dihabiskan, akan tetapi dikembangkan dan digunakan untuk membantu usaha mereka, sehingga dengan usaha tersebut mereka dapat memenuhi kebutuhan hidup secara terus menerus.

Nafiati (2012) dalam penelitianya menjelaskan bahwa zakat produktif dapat digunakan sebagai modal usaha mustahiq dengan cara memberikan bantuan berupa uang tunai sebagai modal usaha. Selain itu, pemberian zakat produktif tersebut dapat bertujuan sebagai dukungan kepada mitra binaan untuk berperan serta dalam upaya untuk pemberdayaan usaha mikro dan pembangunan industri yang ditujukan bagi mustahiq melalui program-program yang bertujuan untuk penciptaan lapangan kerja, peningkatan usaha, dan pelatihan serta pembentuk organisasi.

Tulus Tambunan

(2002:14) menjelaskan bahwa ada dua faktor yang mempengaruhi keberhasilan suatu usaha yaitu faktor internal dan faktor eksternal. Faktor internal merupakan faktor yang berasal dari dalam usaha. Faktor internal meliputi kualitas sdm, penguasaan organisasi, struktur organisasi, sistem manajemen, partisipasi, budaya bisnis, kekuatan modal dan jaringan bisnis dengan pihak luar.

Indikator keberhasilan usaha yang dijelaskan di atas, telah dirangkum oleh Ryanti (2003:28) yaitu :

- peningkatan modal

- peningkatan pendapatan

- peningkatan produksi

- peningkatan jumlah konsumen

- Amal Jariyah Mustahia 
Darmawan, et al/Jurnal Ekonomi Syariah Teori dan Terapan Vol. 6 No. 11 November 2019: 2291-2302; ZAKAT PRODUKTIF DALAM KEBERHASILAN USAHA MUSTAHIQ DITINJAU DARI INDIKATOR PENINGKATAN MODAL, PENINGKATAN PENDAPATAN, PENINGKATAN JUMLAH KONSUMEN, PENINGKATAN PRODUKSI DAN PENINGKATAN AMAL JARIYAH MUSTAHIQ (STUDI KASUS LAZ INISIATIF ZAKAT INDONESIA CABANG JAWA TIMUR)

Dalam penelitian ini indikator dalam menentukan keberhasilan usaha menggunakan pendapat diatas tersebut yaitu bahwa indikator keberhasilan usaha meliputi peningkatan modal, peningkatan pendapatan, peningkatan produksi dan pendapatan jumlah konsumen serta peningkatan amal jariyah mustahiq. Pendapat Ryanti ini dirasa cukup signifikan untuk menentukan keberhasilan usaha.

\section{METODE PENELITIAN}

Pendekatan penelitian sangat penting dalam suatu penelitian karena untuk menentukan arah dari suatu penelitian. Dalam penelitian ini digunakan pendekatan metode kualitatif deskriptif. Penelitian ini dilaksanakan untuk menjawab rumusan masalah yaitu bagaimana peran LAZ dalam mengelola dana zakat produktif terhadap keberhasilan usaha mustahiq. Studi kasus merupakan strategi yang lebih cocok bila pokok pertanyaan suatu penelitian berkenaan dengan how atau why, bila peneliti hanya memiliki sedikit peluang untuk mengontrol peristiwaperistiwa yang akan diselidiki, dan apabila peneliti terlibat langsung dalam penelitian, dan bilamana fokus penelitian terletak pada fenomena kontemporer (masa kini) di dalam konteks kehidupan nyata, serta terdapat proposisi di dalamnya (Yin, 2009:1-2). Di dalam penelitian ini digunakan studi kasus deskriptif yang bertujuan untuk menjelaskan dan menggambarkan peran LAZ dalam mengelola dana zakat produktif terhadap keberhasilan usaha mustahiq.

Pendekatan kualitatif adalah pendekatan dengan menggunakan data yang berupa kalimat tertulis atau lisan, persitiwa-peristiwa, pengetahuan atau proyek studi yang bersifat deskriptif. Penelitian ini berawal dari pencarian data berupa perspektif narasumber dalam bentuk cerita secara detail dan atau cerita asli mereka, kemudian peneliti bersama para narasumber akan memberi penafsiran sehingga menciptakan konsep sebagai temuan. Menurut Sugiyono (2015:1) metode penelitian kualitatif adalah penelitian yang bermaksud untuk memahami fenomena tentang apa yang dialami oleh objek penelitian secara alamiah, dan peneliti merupakan key instrument.

Dalam penelitian kualitatif data dibagi menjadi 2, yaitu data primer dan data sekunder. Data primer adalah data yang didapat dan dikumpulkan dari sumber pertama atau diperoleh secara langsung dari sumber asli. Sedangkan data sekunder adalah data yang telah dikumpulkan oleh pihak lain dan merupakan data tidak langsung yang diberikan kepada pengumpul data (Sugiyono, 2015:62). Sumber dan jenis data dalam penelitian diperoleh dengan cara sebagai berikut:

1. Data Primer 
Darmawan, et al/Jurnal Ekonomi Syariah Teori dan Terapan Vol. 6 No. 11 November 2019: 2291-2302;

ZAKAT PRODUKTIF DALAM KEBERHASILAN USAHA MUSTAHIQ DITINJAU DARI INDIKATOR PENINGKATAN MODAL, PENINGKATAN PENDAPATAN, PENINGKATAN JUMLAH KONSUMEN, PENINGKATAN PRODUKSI DAN PENINGKATAN AMAL JARIYAH MUSTAHIQ (STUDI KASUS LAZ INISIATIF ZAKAT INDONESIA CABANG JAWA TIMUR)

Dalam penelitian ini data primer berasal dari key informan (informan kunci), informan kedua dan ketiga yaitu pengelola LAZ yang memahami program pengelolaan dan pendistribusian dari dana zakat produktif untuk bidang ekonomi melalui program pemberdayaan modal. Dari objek penelitian ini diharapkan mendapatkan informasi mengenai bagaimana program yang dilakukan oleh LAZ IZI dalam mengelola dan mendistribusikan dana zakat produktif. Informan lainnya adalah para mustahiq yang merupakan peserta penerima permodalan yang mendapat pembinaan dan pelatihan program dari LAZ IZI. Dari objek penelitian ini diharapkan mendapatkan informasi dari pengeloaan dan pendistribusian dana zakat produktif untuk bidang ekonomi yang sesuai dengan syariat Islam yang akan menciptakan keberhasilan terhadap usaha mustahiq.

2. Data Sekunder

Dalam penelitian ini data sekunder berasal dari dokumen-dokumen informasi yang diperoleh dari LAZ IZI mengenai data-data penerima pembiayan modal. Selain itu peneliti dapat memperoleh data melalui rekaman dan dokumentasi pribadi. Peneliti juga dapat memperoleh informasi melalui buku-buku terkait zakat, jurnal, internet, makalah, dan literatur atau kajian pustaka yang relevan atau berkaitan dengan permasalahan.

Proses analisis data dilakukan sejak sebelum memasuki lapangan, selama melakukan penelitian, dan melakukan interpretasi dari hasil penelitian yang didapat sesuai dengan tujuan penelitian (Sugiyono, 2015:89). Ada tiga macam bentuk teknik analisis yang sering dipergunakan yaitu penjodohan pola, pembuatan penjelasan, dan analisis deret waktu (Yin, 2009:13). Dalam penelitian ini peneliti menggunakan teknik analisis pembuatan penjelasan (NaratifDeskriptif) atau dengan cara pembuatan penjelasan yang dilakukan melalui metode analisis data dan mendeskripsikan hasil dari wawancara yang bertujuan untuk mengetahui secara mendalam mengenai peran LAZ dalam mengelola dana zakat produktif terhadap keberhasilan usaha mustahia di Kota Surabaya dengan menggunakan studi kasus LAZ IZI.

Langkah terakhir adalah proses penyajian data berupa interpretasi hasil wawancara dalam sebuah tabel dan narasi deskriptif sehingga dapat dengan mudah dipahami oleh semua pihak yang membaca hasil penelitian ini.
IV.
ANALISIS
DAN
PEMBAHASAN HASIL WAWANCARA 
Darmawan, et al/Jurnal Ekonomi Syariah Teori dan Terapan Vol. 6 No. 11 November 2019: 2291-2302; ZAKAT PRODUKTIF DALAM KEBERHASILAN USAHA MUSTAHIQ DITINJAU DARI INDIKATOR PENINGKATAN MODAL, PENINGKATAN PENDAPATAN, PENINGKATAN JUMLAH KONSUMEN, PENINGKATAN PRODUKSI DAN PENINGKATAN AMAL JARIYAH MUSTAHIQ (STUDI KASUS LAZ INISIATIF ZAKAT INDONESIA CABANG JAWA TIMUR)

Penelitian ini dilakukan dengan tujuan untuk mengetahui peran zakat produktif terhadap keberhasilan usaha mustahiq di Kota Surabaya. Dalam penelitian ini, peneliti melakukan wawancara kepada beberapa informan yang dirasa dapat mencapai hasil temuan. Objek penelitian yang ditetapkan adalah LAZ Inisiatif Zakat Indonesia dan subjek penelitian ini menggunakan satu orang key informan yang dapat memberikan informasi yang dibutuhkan peneliti secara mendalam khususnya dalam pengelolaan dan pendistribusian zakat produktif dalam bidang ekonomi di LAZ IZI Jatim Kota Surabaya. Selain itu peneliti juga menggunakan beberapa informan internal lainnya yang juga bekerja pada LAZ IZ cabang Jawa Timur yang bisa memberikan informasi tambahan mengenai program-program yang ada di LAZ IZI cabang Jawa Timur. Kemudian beberapa informan eksternal lainnya yang merasakan adanya peran zakat produktif dalam keberhasilan usaha mustahiq di Kota Surabaya, atau mustahiq pada program ekonomi. Dalam penelitian ini informan yang peneliti wawancarai berjumlah 6 orang yang yang terdiri dari 1 orang Kepala Bidang Kemitraan dan Edukasi Zakat LAZ IZI cabang Jawa Timur, 1 orang kepala bidang Program pemberdayaan bidang ekonomi, 1 orang penanggung jawab Program lapak berkah, dan 3 orang mustahiq yang telah merasakan adanya peran zakat produktif dalam keberhasilan usaha mustahiq. Wawancara tersebut dilakukan peneliti kepada informan secara sukarela dan dengan persetujuan dari para informan tanpa ada hal yang ditambahkan ataupun dikurangi.

$$
\text { Setelah peneliti melakukan }
$$
wawancara kepada informan yang sudah ditentukan dan melakukan survey ke tempat penelitian, peneliti mendapatkan informasi dan data mengenai penyaluran dana zakat dari LAZ Inisiatif Zakat Indonesia. LAZ IZI menyalurkan dana zakat yang sudah dihimpun melalui berbagai macam program yang sudah dibuat. Berikut dibawah ini merupakan table penyaluran dana zakat oleh LAZ IZI kepada mustahiq sesuai dengan bidang dan program.

\section{Tabel 3.}

Penyaluran Dana Zakat Pada Program Berdasarkan Jumlah Nominal 2018

\begin{tabular}{|c|l|c|c|c|c|}
\hline NO & Program & Rencana (Rp) & Realisasi (Rp) & $\begin{array}{c}\text { Capaian } \\
(\%)\end{array}$ & $\begin{array}{c}\text { Penyaluran } \\
(\%)\end{array}$ \\
\hline 1 & Kesehatan & 10.139 .850 .000 & 11.096 .811 .066 & 109 & 39.4 \\
\hline 2 & Pendidikan & 3.941 .275 .000 & 4.030 .354 .101 & 102 & 14,3 \\
\hline 3 & Ekonomi & 3.943 .275 .000 & 4.275 .390 .076 & 108 & 15,1 \\
\hline 4 & Dakwah & 10.139 .850 .000 & 8.741 .147 .811 & 86 & 31,1 \\
\hline & Total & 28.164 .250 .000 & 28.143 .703 .054 & - & - \\
\hline
\end{tabular}


Darmawan, et al/Jurnal Ekonomi Syariah Teori dan Terapan Vol. 6 No. 11 November 2019: 2291-2302; ZAKAT PRODUKTIF DALAM KEBERHASILAN USAHA MUSTAHIQ DITINJAU DARI INDIKATOR PENINGKATAN MODAL, PENINGKATAN PENDAPATAN, PENINGKATAN JUMLAH KONSUMEN, PENINGKATAN PRODUKSI DAN PENINGKATAN AMAL JARIYAH MUSTAHIQ (STUDI KASUS LAZ INISIATIF ZAKAT INDONESIA CABANG JAWA TIMUR)

Sumber : Annual Report Inisiatif Zakatm Indonesia 2018, Diolah Peneliti.

Melihat pada Tabel 3 bahwa pada tahun 2018 zakat produktif yang disalurkan LAZ IZI pada bidang ekonomi sebesar Rp 3.943.275.000. Jika melihat dari besar total penyaluran kepada empat bidang yaitu bidang kesehatan, bidang pendidikan, bidang ekonomi dan bidang dakwah yang berjumlah Rp 28.164.250.000 maka penyaluran pada bidang ekonomi menempati urutan ekonomi dimana penyaluran zakat produktif terbesar yaitu pada bidang kesehatan.

Tabel 4.

Bentuk Program Pemberdayaan IZI Jawa Timur

\begin{tabular}{|c|c|c|c|}
\hline $\mathbf{N}$ & Program & Target & $\begin{array}{l}\text { Bentuk } \\
\text { Pemberdaya } \\
\text { an }\end{array}$ \\
\hline 1 & $\begin{array}{l}\text { Rumah } \\
\text { Bina } \\
\text { Sejahtera } \\
\text { h }\end{array}$ & $\begin{array}{l}\text { Kelompo } \\
\mathrm{k}\end{array}$ & $\begin{array}{l}\text { Dibangunkan } \\
\text { peternakan } \\
\text { disuatu } \\
\text { daerah, lalu } \\
\text { dikelola } \\
\text { secara } \\
\text { bersama/ } \\
\text { kelompok } \\
\text { dan di awasin } \\
\text { oleh pihak Izl } \\
\text { secara rutin. }\end{array}$ \\
\hline 2 & $\begin{array}{l}\text { Lapak } \\
\text { Berkah }\end{array}$ & Individu & $\begin{array}{l}\text { Diberikan } \\
\text { permodalan } \\
\text { berbentuk } \\
\text { barang/ } \\
\text { benda, } \\
\text { contohnya } \\
\text { seperti } \\
\text { gerobak, } \\
\text { alat2 untuk } \\
\text { berdagang, } \\
\text { dll. Serta } \\
\text { pembinaan } \\
\text { dan pelatihan } \\
\text { serta evaluasi }\end{array}$ \\
\hline
\end{tabular}

Sumber : Hasil Wawancara, Diolah Peneliti
Standar keberhasilan usaha mustahiq adalah standar yang berkaitan dengan peningkatan modal, peningkatan pendapatan, peningkatan produksi, peningkatan jumlah konsumen dan Amal Jariyah Mustahiq. Standar keberhasilan akan tercapai jika indikator berkaitan dengan mekanisme, prosedur dan penyaluran berjalan dengan benar dan tepat.

Keberhasilan usaha yang telah dicapai oleh mustahiq juga tak lepas dari peran LAZ IZI Jatim yang selalu mendampingi dan mengawasi usaha yang dijalankan oleh mustahiq. Pihak LAZ IZI Jatim selalu memberikan motivasi dan semangat kepada seluruh mustahiq, serta memberikan bantuan pemasaran terhadap produk mustahiq yang dijual nantinya. Lalu dimana semua para mustahiq mengalami semua peningkatan pada indikator yang sudah disebutkan, maka mustahiq sudah dikatakan wajib untuk mebyisihkan sebagaian hartanya untuk berinfaq dan bersedekah. Dengan demikian pemberian motivasi dan semangat tersebut bertujuan agar kelak mustahiq dalam menjalankan usahanya menuai keberhasilan.

\section{SIMPULAN}

\section{Kesimpulan}

Berdasarkan dari hasil dan pembahasan penelitian yang telah dilakukan oleh peneliti, maka peneliti 
Darmawan, et al/Jurnal Ekonomi Syariah Teori dan Terapan Vol. 6 No. 11 November 2019: 2291-2302;

ZAKAT PRODUKTIF DALAM KEBERHASILAN USAHA MUSTAHIQ DITINJAU DARI INDIKATOR PENINGKATAN MODAL, PENINGKATAN PENDAPATAN, PENINGKATAN JUMLAH KONSUMEN, PENINGKATAN PRODUKSI DAN PENINGKATAN AMAL JARIYAH MUSTAHIQ (STUDI KASUS LAZ INISIATIF ZAKAT INDONESIA CABANG JAWA TIMUR)

dapat menarik beberapa kesimpulan yaitu:

1. Bahwa LAZ IZI mampu berperan dalam melakukan pemberdayaan dan penyalurkan dana zakat produktif dengan benar dan tepat sehingga keberhasilan usaha mustahiq dapat tercapai. Lalu informan yang menerima dana bantuan telah menggunakan dan memanfaatkan modal usaha secara proporsional untuk pengembangan usahanya. Hasil penelitian menunjukkan ketiga informan mengalami keberhasilan dalam menjalankan usahanya. Keberhasilan usaha informan dapat dilihat dari peningkatan modal, peningkatan pendapatan, peningkatan produksi, peningkatan jumlah konsumen dan peningkatan amal jariyah. Para informan merasakan adanya perubahan skala dalam usaha yang dijalankan dan perubahan pada kondisi perekonomian keluarga yang lebih baik dari sebelumnya, selain bisa memenuhi kebutuhan sehari-hari juga bisa menyisihkan sebagian hasil harta untuk bersedekah dan mampu membayar infaq secara rutin.

2. Bantuan modal yang diberikan kepada informan bukan merupakan pinjaman modal yang harus dikembalikan melainkan pendistribusian dana zakat produktif yang para informan berhak untuk menerimanya. ketiga informan tidak memiliki kewajiban untuk mengembalikan bantuan modal akan tetapi harus mampu menggunakan dana zakat produktif dengan penuh rasa tanggungjawab dan sebaik-baiknya. Sehingga bisa dapat dikatakan bahwa para informan bisa berbalik menjadi muzzaki.

3. Setiap satu bulan sekali informan akan mendapatkan pengawasan dan pendampingan dari pihak LAZ IZI. Pengawasan dan pendampingan yang dilakukan oleh LAZ IZI dengan cara mendatangi setiap informan dan menanyai bagaimana perkembangan usaha yang dijalankan dan memberikan pengetahuan serta wawasan ceramah seputar agama kepada informan yang di agendakan di masjid dekat rumah informan. Hasil penelitian menunjukkan ketiga informan merasakan manfaat dari pengawasan dan pendampingan yang dilakukan oleh LAZ IZI. Manfaat yang dirasakan oleh informan berupa motivasi dan semangat dalam menjalankan usaha serta mampu menyisihkan sebagian dari hartanya untuk kembali diberikan kepada yang berhak menerima.

\section{Saran}

Berdasarkan dari hasil dan pembahasan penelitian serta 
Darmawan, et al/Jurnal Ekonomi Syariah Teori dan Terapan Vol. 6 No. 11 November 2019: 2291-2302; ZAKAT PRODUKTIF DALAM KEBERHASILAN USAHA MUSTAHIQ DITINJAU DARI INDIKATOR PENINGKATAN MODAL, PENINGKATAN PENDAPATAN, PENINGKATAN JUMLAH KONSUMEN, PENINGKATAN PRODUKSI DAN PENINGKATAN AMAL JARIYAH MUSTAHIQ (STUDI KASUS LAZ INISIATIF ZAKAT INDONESIA CABANG JAWA TIMUR)

wawancara dengan informan, maka timbul beberapa saran bagi beberapa pihak, yaitu:

1. Bagi Lembaga Amil Zakat Inisiatif Zakat Indonesia cabang Jawa Timur disarankan dapat lebih mengoptimalkan pendayagunaan dana zakat produktif dengan menambah jumlah penerima bantuan pemberdayaan dana zakat produktif serta tidak hanya berfokus pada wilayah kota dan pemberdayaan ekonomi desa perlu diperhatikan secara khusus mengingat sebagian besar kondisi perekonomian penduduk desa tersebut masih sangat terbatas, sehingga perlu adanya upaya lebih untuk membangun tingkat perekonomian desa menjadi lebih baik.

2. Para informan disarankan untuk terus mengembangkan usahanya dan membantu memberdayakan masyarakat sekitar yang juga tergolong tidak mampu, sehingga dalam jangka panjang para mustahia dapat mengembangkan usahanya dan mampu meningkatkan derajatnya menjadi muzakki.

3. Pemerintah Kota Surabaya dan dinas terkait juga disarankan turut serta dan mendukung pelaksanaan programprogram kerja yang dilakukan oleh Lembaga Amil Zakat berbasis pemberdayaan dana zakat produktif,
Serta memberikan regulasi, finansial, maupun sosialiasi kepada masyarakat tentang potensi zakat yang sangat besar. Hal ini akan membantu mengurangi permasalahan dan meningkatkan perekonomian yang terjadi di Kota Surabaya.

4. Peneliti selanjutnya disarankan agar dapat meneliti lagi secara mendalam mengenai program kerja Lembaga Amil Zakat yang memberikan bantuan pemberdayaan dana zakat produktif dengan memperhatikan tersedianya pembukuan yang dimiliki oleh pelaku usaha mikro serta mampu menambah informasi mengenai pemberdayaan dana zakat produktif dan pengelolaanya serta juga mempelajari siklus dan mekanisme penyaluran dana zakat produktif tersebut.

\section{DAFTAR PUSTAKA}

Ryanti, Benedicta Prihatin Dwi. 2003.

Kewirausahaan dari Sudut
Pandang Psikologi
Kepribadian. Jakarta:Grasindo

Tambunan, Tulus. 2002. Perdagangan

Internasional dan Neraca
Pembayaran: Teori dan Temuan
Empiris. Jakarta: LP3S

Sugiyono. 2015. Memahami Penelitian Kualitatif. Bandung : Alfabeta

https://izi.or.id

https://kbbi.web.id

https://www.bps.go.id 

JAWA TIMUR)

Sumodiningrat, Gunawan. 1999.

Kemiskinan: Teori, Fakta, dan

Kebijakan. Jakarta: impac.

Nafiati. 2012. Pemberdayaan Mustahiq

Melalui Pendayagunaan Zakat

Produktif (Studi Kasus Baitul

Maal Hudatama Peduli Semarang

Tahun 2011). Skripsi Tidak

diterbitkan. Sleman FE Universitas

IAIN Walisonggo.

Ambara, labal M. 2009. Problematika

Zakat dan Pajak di Indonesia.

Sketsa 